\title{
Xanthine Oxidase Inhibition Attenuates Ischemic-Reperfusion Lung Injury
}

\author{
Martin J. Lynch, M.D., Cyril M. Grum, M.D., Kim P. Gallagher, Ph.D., \\ Steven F. Bolling, M.D., G. Michael DeEb, M.D., ${ }^{1}$ \\ AND MElVin L. MORganroth, M.D.
}

Pulmonary and Critical Care Division, Department of Internal Medicine, Department of Physiology, and Section of Thoracic Surgery, Department of Surgery, University of Michigan Hospitals, Ann Arbor, Michigan 48109

Presented at the Annual Meeting of the Association for Academic Surgery, Orlando, Florida, November 1-4, 1987

\begin{abstract}
Ischemic-reperfusion lung injury is a factor potentially limiting the usefulness of distant organ procurement for heart-lung transplantation. Toxic oxygen metabolites are considered a major etiologic factor in reperfusion injury. Although oxygen-free radicals may be generated by many mechanisms, we investigated the role of xanthine oxidase in this injury process by using lodoxamide, a xanthine oxidase inhibitor, to inhibit ischemic-reperfusion injury in an isolated rat lung model. Isolated rat lungs were perfused with physiologic salt solution (PSS) osmotically stabilized with Ficoll until circulating blood elements were nondetectable in the pulmonary venous effluent. Lungs were rendered ischemic by interrupting ventilation and perfusion for $2 \mathrm{hr}$ at $37^{\circ} \mathrm{C}$. After the ischemic interval, the lungs were reperfused with whole blood and lung injury was determined by measuring the accumulation of ${ }^{125} \mathrm{I}$-bovine serum albumin in lung parenchyma and alveolar lavage fluid as well as by gravimetric measurements. Lung effluent was collected immediately pre- and postischemia for analysis of uric acid by high-pressure liquid chromatography. Lodoxamide $(1 \mathrm{~m} M)$ caused significant attenuation of postischemic lung injury. Uric acid levels in the lung effluent confirmed inhibition of xanthine oxidase. Protection from injury was not complete, however, implying that additional mechanisms may contribute to ischemic-reperfusion injury in the lung. (c) 1988 Academic Press, Inc.
\end{abstract}

\section{INTRODUCTION}

The inability to adequately preserve lungs for transport is a major impediment to wide clinical use of heart-lung transplantation [7]. Contributing to the problem of lung preservation is reperfusion injury which may be superimposed on any ischemic damage affecting transplanted lungs. In contrast to other organ systems, little work has been done to elucidate the mechanism of reperfusion injury in the lung following an episode of ischemia. Data from other models suggest that toxic oxygen metabolites play a role in the mechanism of ischemic-reperfusion injury $[2,12]$. Toxic oxygen metabolites can be generated from many sources, including neutrophils, alveolar macrophages, endothelial cells, and lung parenchymal cells $[3,5,9$, 20, 21]. Previous work from this laboratory

\footnotetext{
${ }^{1}$ To whom correspondence should be addressed at University of Michigan Medical Center, $1500 \mathrm{E}$. Medical Center Drive, 2120 Taubman Health Care Center, Box 0344, Ann Arbor, MI 48109.
}

demonstrated that a non-neutrophil source of toxic oxygen metabolites was responsible for a significant portion of pulmonary ischemic-reperfusion injury. The injury could be readily produced in the absence of circulating blood elements and the addition of neutrophils did not augment the injury [10].

We hypothesized that the toxic oxygen metabolites causing the lung injury were generated during the metabolism of purine degradation products by xanthine oxidase. Xanthine oxidase is formed from xanthine dehydrogenase, by the action of proteases during ischemia [12]. Like xanthine dehydrogenase, xanthine oxidase metabolizes hypoxanthine initially to xanthine and then to uric acid. Unlike xanthine dehydrogenase, however, xanthine oxidase uses $\mathrm{O}_{2}$ as its electron acceptor, generating superoxide anion and hydrogen peroxide during this process [13]. These oxygen metabolites can be further metabolized into other species, including the highly toxic hydroxyl radical [13, $16,18,21]$. To test the hypothesis that me- 
tabolism of purine degradation products by xanthine oxidase was responsible for the ischemic-reperfusion injury, we administered lodoxamide, an inhibitor of xanthine oxidase, to evaluate its efficacy in attenuating lung injury.

\section{MATERIALS AND METHODS}

Ex vivo lung preparation. An ex vivo model was used to assess reperfusion lung injury after an ischemic insult. Lungs were isolated from male Long Evans rats (175-300 g) which had been anesthetized with pentobarbital $(40 \mathrm{mg} / \mathrm{kg}$ intraperitoneally). The lungs were isolated and perfused at a constant flow of $0.03 \mathrm{ml} / \mathrm{g}$ rat body wt $/ \mathrm{min}$ as previously described [14, 15]. Mean pulmonary artery inflow pressure was measured with a Statham transducer and recorded on a Grass recorder. Left atrial pressure (pulmonary outflow) was set by adjusting the height of the outflow reservoir. Except where specified, left atrial pressure was $0 \mathrm{~mm} \mathrm{Hg}$. The lungs were ventilated at $9 \mathrm{~cm}$ of water pressure with a positive-end expiratory pressure of $1 \mathrm{~cm}$ of water via a tracheal cannula with an air/gas mixture containing $21 \% \mathrm{O}_{2}$ and $5 \% \mathrm{CO}_{2}$ at a rate of 60 strokes/min, using a Harvard animal respirator. Lungs were perfused with physiologic salt solution (PSS) osmotically stabilized with Ficoll $(4 \mathrm{~g} / 100 \mathrm{ml})$ at $37^{\circ} \mathrm{C}$. The first $25 \mathrm{ml}$ of pulmonary venous effluent was discarded to eliminate rat blood elements from the lung vasculature. The final $2 \mathrm{ml}$ of pulmonary venous effluent (blood-free) was collected prior to the onset of the ischemic period for the measurement of uric acid.

Lung ischemia. Ischemic injury was induced by stopping ventilation and perfusion for $120 \mathrm{~min}$. The lungs were inflated with 3 cc of room air at the start of the ischemic period and the tracheal cannula was occluded, so that the lungs remained inflated. This was done to facilitate reperfusion following the ischemic insult. To avoid desiccation during ischemia, the lungs were intermittently sprayed with nonoxygenated sterile normal saline at $37^{\circ} \mathrm{C}$.
Lung reperfusion. Lungs were reperfused with heparinized homologous blood at $37^{\circ} \mathrm{C}$. Reperfusion after ischemia was started slowly and the flow rate was increased such that a pressure greater than $30 \mathrm{~mm} \mathrm{Hg}$ was never exceeded. The first $2 \mathrm{ml}$ of pulmonary venous effluent (blood-free) was collected and assayed for uric acid produced during ischemia. Within $10 \mathrm{~min}$ of the onset of reperfusion the flow rate was increased to the same flow rate used prior to ischemia. Lungs were perfused for $30 \mathrm{~min}$ to reach a stable perfusion pressure and temperature prior to adding ${ }^{125} \mathrm{I}$-bovine serum albumin $\left({ }^{125} \mathrm{I}\right.$-BSA) to the blood perfusate for the assessment of lung injury (described below). Simultaneously with the onset of reperfusion, lung ventilation was resumed with a gas mixture containing $21 \% \mathrm{O}_{2}$ and $5 \% \mathrm{CO}_{2}$.

Experimental groups. Three experimental groups were studied. The first group of five animals underwent $120 \mathrm{~min}$ of ischemia followed by reperfusion (ISCH). In the second group (of five animals) the same protocol was followcd with the exception that lodoxamide (UpJohn Corp., Kalamazoo, MI), at a concentration of $1 \mathrm{~m} M$, was added to all pre- and postischemic solutions (ISCH/ LODOX). A third group of four nonischemic controls (CONT) consisted of lungs harvested and flushed with PSS/Ficoll in an identical manner, and then perfused with homologous whole blood at $37^{\circ} \mathrm{C}$ for 120 ( $n$ $=1)$ or $150(n=3)$ min prior to adding ${ }^{125} \mathrm{I}$ BSA to the blood perfusate. Perfusion and ventilation were never interrupted in the nonischemic control group. The perfusion time of $150 \mathrm{~min}$ was equal to the length of time the ischemic lungs were ex vivo before ${ }^{125}$ I-BSA was added to assay for lung injury.

Measurement of lung injury. Lung injury was assessed after $30 \mathrm{~min}$ of normothermic reperfusion (ISCH and ISCH/LODOX) or at the end of the 150-min control period (CONT). Lung injury was measured by the accumulation of ${ }^{125} \mathrm{I}$-BSA in lung parenchyma and alveolar lavage fluid over the 30 min period following the addition of ${ }^{125} \mathrm{I}$ BSA to the lung perfusate. Three measurements were performed to assay lung injury: 
(a) the amount of ${ }^{125}$ I-BSA that accumulated in lung parenchyma, (b) the amount of ${ }^{125} \mathrm{I}-$ BSA that accumulated in alveolar lavage fluid, and (c) the ratio of wet lung weight to rat body weight.

${ }^{125}$ I-BSA was prepared by the standard chloramine $\mathrm{T}$ method. Unbound iodine was removed by gel filtration using a G-75 column. At the same time that ${ }^{125}$ I-BSA was added to the lung perfusate, the reservoir draining the pulmonary venous effluent was raised $8 \mathrm{~cm}$ above the level of the left atrium. The reservoir height was changed because small increases in left atrial pressure should markedly increase lung water and accumulation of ${ }^{125} \mathrm{I}$-BSA in lungs with increased vascular permeability (ischemic), but cause only small changes in lungs with normal vascular permeability (nonischemic). Thus, lungs with increased vascular permeability would be more easily identified. Once elevated, the reservoir remained elevated for the remainder of the experiment. Thirty minutes after the addition of ${ }^{125} \mathrm{I}$-BSA, $1 \mathrm{ml}$ of pulmonary venous effluent was obtained, weighed, and counted for $2 \mathrm{~min}$ in a gamma scintillation counter. This allowed the determination of the number of ${ }^{125} \mathrm{I}$-BSA counts in $1.0 \mathrm{~g}$ of circulating perfusate.

The reservoir supplying perfusate to the lung was then clamped and a reservoir containing PSS osmotically stabilized with Ficoll ( $4 \mathrm{~g} / 100$ $\mathrm{ml}$ ) was used to perfuse the lung at the same rate used throughout the experiment. After perfusion with $25 \mathrm{ml}$ of this solution (containing no ${ }^{125} \mathrm{I}$-BSA) $1.0 \mathrm{ml}$ of pulmonary venous effluent was obtained and measured for radioactivity in the gamma scintillation counter. This was performed to confirm that minimal ${ }^{125}$ I-BSA counts ( $1 \%$ or less of the counts present in $1.0 \mathrm{~g}$ of the circulating perfusate) remained within the intravascular space of the lung. The lungs and attached structures were then weighed before performing whole lung lavage. Lung lavage was done by repeatedly instilling and withdrawing $3 \mathrm{ml}$ of normal saline through the tracheal cannula. One milliliter of the recovered lavage fluid was counted for $2 \mathrm{~min}$ in a gamma scintillation counter to measure the amount of ${ }^{125}$ I-BSA that had ac- cumulated in alveolar lavage fluid. The lung was dissected from the attached structures and the lung tissue itself was counted for $2 \mathrm{~min}$ in a gamma scintillation counter to measure the amount of ${ }^{125}$ I-BSA that had accumulated in lung parenchyma. The attached structures dissected from the lung tissue were weighed, and this weight was subtracted from the previously determined weight of the lung plus attached structures, to determine lung wet weight.

${ }^{125} \mathrm{I}$-BSA counts present in alveolar lavage fluid, lung tissue, and pulmonary venous effluent were normalized by dividing the number of counts measured by the number of ${ }^{125} \mathrm{I}-\mathrm{BSA}$ counts present in $1.0 \mathrm{~g}$ of circulating perfusate. The ratio of lung wet weight to rat body weight was calculated as an index of lung water.

Electron microscopy. Transmission electron microscopy was performed to survey the ultrastructural pattern of lung injury that was produced and to determine whether or not the damage was altered by lodoxamide. Electron microscopy was performed in lungs subjected to $30 \mathrm{~min}$ of reperfusion following $120 \mathrm{~min}$ of ischemia at $37^{\circ} \mathrm{C}$, with $1 \mathrm{mM}$ lodoxamide present or absent in the blood perfusate. The lung was fixed with glutaraldehyde via tracheal instillation (at $15 \mathrm{~cm}$ $\mathrm{H}_{2} \mathrm{O}$ ) and then processed for light and electron microscopy [20].

Uric acid analysis. Uric acid was measured in the lung effluent. Timed collections of 2 $\mathrm{ml}$ each were placed in prechilled tubes. Samples were centrifuged at $5000 \mathrm{~g}$ for 10 min at $4^{\circ} \mathrm{C}$ to remove cellular debris, and stored at $-70^{\circ} \mathrm{C}$ until assayed. The concentrations of uric acid were determined by high-pressure liquid chromatography as previously described [6]. A liquid chromatograph system was used with a Waters Micro Bondapak C-18 10- $\mu \mathrm{m}$ particle-sized column $(3.9 \mathrm{~mm} \times 30 \mathrm{~cm})$. The column was eluted with acetonitrile at a flow rate of $1.5 \mathrm{ml} / \mathrm{min}$. The absorbance of the column effluent was monitored at $254 \mathrm{~nm}$.

Statistics. Values were expressed as mean \pm SEM. Groups were compared using oneway analysis of variance and the Newman- 
TABLE 1

PRotective EFFECTS OF LODOXAMIDE IN LUNG ISCHEMIC-REPERFUSION INJURY [Lodoxamide] $=1 \mathrm{~m} M$

\begin{tabular}{|c|c|c|c|c|c|}
\hline \multirow[b]{2}{*}{ Groups $^{a}$} & \multicolumn{2}{|c|}{ Albumin leak indices } & \multirow{2}{*}{$\begin{array}{l}\text { Wet lung } \\
\text { to rat body } \\
\text { wt ratio }\end{array}$} & \multirow{2}{*}{$\begin{array}{c}\text { Peak PA } \\
\text { pressure } \\
\text { postischemia } \\
(\mathrm{mm} \mathrm{Hg})\end{array}$} & \multirow{2}{*}{$\begin{array}{l}\text { Mean PA pressure } \\
\text { during }{ }^{125} \mathrm{I}-\mathrm{BSA} \\
\text { accumulation } \\
(\mathrm{mm} \mathrm{Hg})\end{array}$} \\
\hline & $\begin{array}{l}\text { Lung } \\
\text { parenchyma }\end{array}$ & $\begin{array}{l}\text { Alveolar } \\
\text { lavage }\end{array}$ & & & \\
\hline CONT & $0.17 \pm 0.04^{d}$ & $0.006 \pm 0.001^{d}$ & $5.1 \pm 0.48^{d}$ & $10 \pm 1^{c, d}$ & $15 \pm 1^{d}$ \\
\hline ISCH & $0.91 \pm 0.15$ & $0.156 \pm 0.29$ & $19 \pm 2.84$ & $20 \pm 2$ & $20 \pm 1$ \\
\hline ISCH/LODOX & $0.35 \pm 0.05^{d}$ & $0.029 \pm 0.003^{d}$ & $10.4 \pm 0.83^{d}$ & $17 \pm 1^{e}$ & $15 \pm 1^{d}$ \\
\hline
\end{tabular}

${ }^{a}$ These groups are described under Materials and Methods.

${ }^{b}$ PA pressure was measured in all groups at a flow of $0.03 \mathrm{ml} / \mathrm{g}$ rat body $\mathrm{wt} / \mathrm{min}$.

${ }^{C}$ Peak pressure reached in the absence of an ischemic insult.

${ }^{d} P<0.05$ compared to ISCH.

${ }^{e} P<0.06$ compared to ISCH.

Keuls multiple comparison test. A $P$ value less than 0.05 was accepted as significant.

\section{RESULTS}

Within 10 min of the onset of reperfusion the blood flow rate was increased to the same flow rate used prior to ischemia. At the same time that this flow rate $(0.03 \mathrm{ml} / \mathrm{g}$ rat body $\mathrm{wt} / \mathrm{min}$ ) was achieved, mean pulmonary artery pressure (PA) was maximal in lungs subjected to the ischemic insult (Table 1). The corresponding PA pressure in control lungs (not subjected to an ischemic insult) was significantly lower (Table 1). Mean pulmonary artery pressure in the ischemic lungs then decreased toward baseline during the next 10 min of perfusion. At the end of this 10 -min period the PA pressure was $16 \pm 2$ $\mathrm{mm} \mathrm{Hg}$ which was significantly greater than pressure in the control lungs $(8 \pm 0.2 \mathrm{~mm}$ $\mathrm{Hg}$ ). PA pressure then remained stable.

Significant lung injury occurred during the reperfusion of lungs subjected to the ischemic insult. There was increased accumulation of ${ }^{125}$ I-BSA in lung parenchyma and alveolar lavage fluid compared to the nonischemic control lungs as summarized in Table 1. Lung water was also increased as determined by an increase in lung wet weight to rat body weight in lungs reperfused following an ischemic insult. Lung injury was also evident by ultrastructural changes during reper- fusion following the ischemic insult (Fig. 1). Endothelial and epithelial injury as well as alveolar hemorrhage werc evident.

PA pressure at the time full flow was reached during reperfusion was lower in lungs treated with lodoxamide but still greater than in the control lungs (Table 1). However, PA pressure 10 min later $(12 \pm 1$ $\mathrm{mm} \mathrm{Hg}$ ) was not different either from the ischemic lungs treated with lodoxamide or from the control lungs. The elevation in lung wet weight to rat body weight and increased accumulation of ${ }^{125}$ I-BSA in lung parenchyma and alveolar lavage fluid were also attenuated by lodoxamide. Lodoxamide also markedly attenuated the endothelial and epithelial cell injury. Alveolar hemorrhage was not seen (Fig. 1).

The alterations in accumulation of ${ }^{125} \mathrm{I}$ BSA in lung parenchyma and alveolar lavage fluid could have been due in part to changes in hydrostatic pressure as well as alterations in permeability secondary to endothelial and epithelial injury. Although the PA pressures during the period of ${ }^{125}$ I-BSA accumulation were different in the control lungs and in lungs subjected to an ischemic insult in the presence or absence of lodoxamide (Table 1), the differences in pressure were small. To evaluate this issue in more detail, lung albumin accumulation was compared in a subset of lungs from each of these groups (ISCH vs ISCH/LODOX). Lungs were paired such 


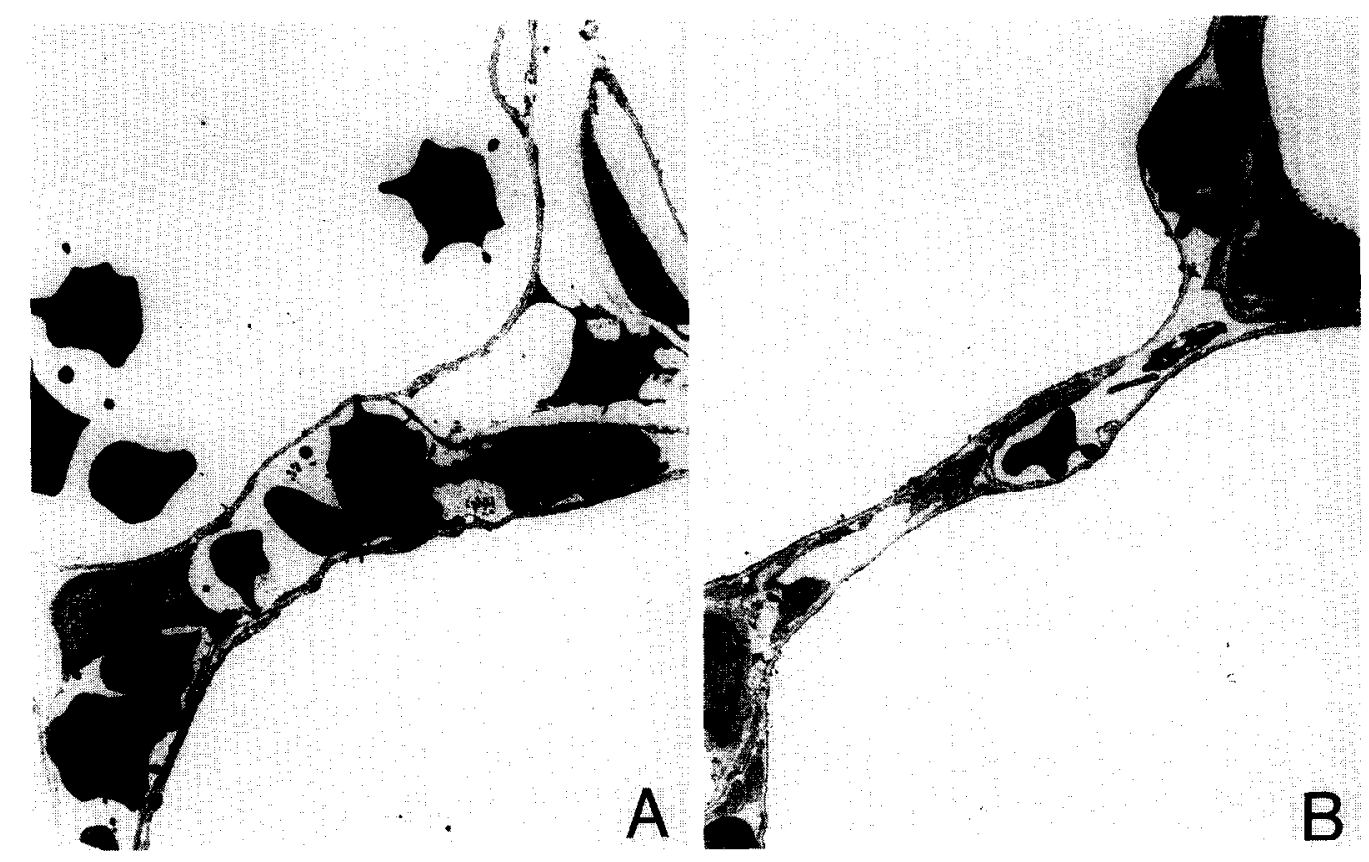

FIG. 1. Transmission electron microscopy of rat lung after $120 \mathrm{~min}$ of ischemia followed by $30 \mathrm{~min}$ of reperfusion. (A) A representative lung without lodoxamide. It shows intraalveolar hemorrhage, marked interstitial edema, and endothelial cell alterations as evidenced by exposed basement membranes, blebbing, and necrotic cytoplasm. (B) A lung subjected to identical conditions except that lodoxamide (1 m $M$ ) was present in the perfusate before and after ischemia. Marked attenuation of injury is seen. The stain is uranyl acetate/lead citrate at $3600 \times$ magnification.

that mean PA pressures during the period of ${ }^{125}$ I-BSA accumulation were not significantly different ( $\leqslant 1 \mathrm{~mm} \mathrm{Hg}$ difference). In comparing these groups (paired $t$ tests, $n=3$ ) we observed that lungs in the ISCH/LODOX group lungs still had less $(P<0.05){ }^{125} \mathrm{I}-\mathrm{BSA}$ accumulation in lung parenchyma $(0.42$ $\pm 0.04)$ and alveolar lavage fluid $(0.034$ \pm 0.003 ), when compared to lungs in the ISCH group (1.11 $\pm 0.16,0.193 \pm 0.033)$.

Uric acid levels. Uric acid was not detected in any perfusates preischemia. Postischemia, uric acid levels in the ISCH group were 38.8 $\pm 5.7 \mu M$. In the ISCH/LODOX group, postischemic uric acid levels decreased to 20.9 $\pm 4.5 \mu M$, a statistically significant decrease (Table 2).

\section{DISCUSSION}

Our results suggest that the enzyme xanthine oxidase participates in ischemic-reper- fusion lung injury. Lodoxamide, an inhibitor of xanthine oxidase [22], significantly attenuated ischemic-reperfusion injury. This was manifested by decreased pulmonary vascular resistance as well as decreased albumin accumulation in the lung parenchyma and alveolar space. In addition, electron microscopic examination of tissue samples showed that

TABLE 2

Results of Uric ACID Measurements Pre- AND POSTISCHEMIA IN GROUPS WITH AND WITHOUT LODOXAMIDE ( $n=5$ IN ALL GROUPS)

\begin{tabular}{lc}
\hline \multicolumn{1}{c}{ Groups } & $\begin{array}{c}\text { Uric acid } \\
\text { level }(\mu M)\end{array}$ \\
\hline ISCH (Preischemia) & 0 \\
ISCH (Postischemia) & $38.8 \pm 5.7$ \\
ISCH/LODOX (Preischemia) & 0 \\
ISCH/LODOX (Postischemia) & $20.9 \pm 4.5^{a}$ \\
\hline
\end{tabular}

${ }^{a} P<0.05$ compared to ISCH. 
the severe endothelial and epithelial injury in the ISCH group was markedly attenuated in the ISCH/LODOX perfused lungs. To document that lodoxamide inhibited xanthine oxidase, uric acid levels were measured, demonstrating that we had successfully achieved at least partial inhibition of the enzyme.

Other investigators have implicated xanthine oxidase in ischemic heart and intestinal injury $[1,12,16,17]$. Attenuation of pulmonary injury using lodoxamide in our study coupled with the decrease in uric acid production is strong evidence that the xanthine oxidase hypothesis can now be extended to ischemic-reperfusion injury in the rat lung. We acknowledge, however, that alternative means of inhibiting xanthine oxidase will be required to verify this conclusion.

It is likely that the mechanism of xanthine oxidase injury is through generation of toxic oxygen metabolites $[2,12]$. During ischemia, xanthine dehydrogenase is converted to xanthine oxidase which uses molecular oxygen as its electron acceptor, leading to the generation of hydrogen peroxide and superoxide anion [12], toxic oxygen species that can be further metabolized to the highly reactive hydroxyl radical [11-13]. Ischemia also precipitates a cascade of purine nucleotide breakdown which supplies substrates for xanthine oxidase [4]. Although we have shown that xanthine oxidase plays a role in ischemic reperfusion injury, it is probably not the sole source of injury as protection from injury was not complete. Alternatively, lodoxamide inhibition of xanthine oxidase may not have been complete. It is likely that many mechanisms contribute to this injury, although we have recently shown that neutrophils are not a factor in this model [10].

We speculate that oxygen radicals increased vascular permeability and alveolar leakage of protein by damaging lung endothelial and epithelial cells $[19,20]$. As demonstrated in the electron micrographs (Fig. 1), destruction of alveolar architecture was prominent in the ISCH example, whereas the ISCH/LODOX example was characterized by nearly normal architecture. Thus, the an- atomic findings also support the possibility, based on ${ }^{125}$ I-BSA accumulation and gravimetric mcasurements, that oxygen radicals alter vascular permeability. Pulmonary artery pressures during ${ }^{125}$ I-BSA accumulation were slightly higher in the ISCH and CONT groups than in the ISCH/LODOX group, suggesting that differences in hydrostatic pressures could have accounted for the elevated accumulation of ${ }^{125}$ I-BSA rather than damage to endothelial and epithelial cells. However, when data from the ISCH/ LODOX group were compared with those from the ISCH group at equivalent PA pressures, the leak indices were still dramatically different. Therefore, it is unlikely that differences in lung injury measurements can be explained by changes in hydrostatic pressures.

Ischemic-reperfusion lung injury is a factor limiting the usefulness of distant organ procurement for heart-lung transplantation [7]. If the mechanisms causing this injury were known then specific interventions might be developed to prevent the injury. Our findings suggest that the use of xanthine oxidase inhibitors may be one such intervention. Although the use of an isolated rat lung model allows identification of specific mechanisms, extension of these findings to intact animals must be done with caution. Species variability in purine biochemistry $[6,8]$ and the role of mechanical factors such as lung size must be examined to determine the relevance of our findings to human transplantation.

\section{ACKNOWLEDGMENTS}

Supported in part by Clinical Investigator Awards from the NIH, HL 01595 (MLM) and HL 01930 (CMG); The American Heart Association; the American Lung Association; and the Fellowship from The American Heart Association of Michigan.

\section{REFERENCES}

1. Chambers, D. E., Parks, D. A., Patterson, G., Roy, R., McCord, J. M., Yoshida, S., Parmley, L. F., and Downey, J. M. Xanthine oxidase as a source of free radical damage in myocardial ischemia. J. Mol. Cell. Cardiol. 17: 145, 1985. 
2. Cross, C. E. Moderator, Oxygen radicals and human disease. Ann. Intern. Med. 107: 526, 1987.

3. Fantone, J. C., and Ward, P. A. Role of oxygen-derived free radicals and metabolites in leucocyte-dependent inflammatory reactions. Amer. J. Pathol. 107: 397, 1982.

4. Fox, 1. H. Metabolic basis for disorders of purine nucleotide degradation. Metabolism 30: 616, 1981.

5. Freeman, B. A., and Tanswell, A. N. Biochemical and cellular aspects of pulmonary oxygen toxicity. Adv. Free Radical Biol. Med. 1: 133, 1985.

6. Grum, C. M., Ketai, L., Myers, C. L., and Shlafer, M. Purine efflux after cardiac ischemia: Relevance to allopurinol cardioprotection. Amer. J. Physiol. 252: 368, 1987.

7. Haverick, A., Scott, W. C., and Jawdeson, S. W. Twenty years of lung preservation-A review. $J$. Ileart Transplant. 4: 234, 1985.

8. Huh, K., Yamamoto, I., Gohda, E., and Iwata, H. Tissue distribution and characteristics of xanthine oxidase and allopurinol oxidizing enzyme. Japan J. Pharmacol. 26: 719, 1976.

9. Johns, K. J., Wilson, B. S., Till, G. O., and Ward, $P$. A. Acute lung injury in rat caused by immunoglobulin A immune complexes. J. Clin. Invest. 74: $358,1984$.

10. Lynch, M. J., Grum, C. M., Gallagher, K. P., Deeb, G. M., and Morganroth, M. L. A non-neutrophil source of toxic oxygen metabolites is involved in ischemic reperfusion lung injury. Manuscript submitted for publication.

11. McCord, J. M. The superoxide free radical: Its biochemistry and pathophysiology. Surgery 94: 412, 1983.

12. McCord, J. M. Oxygen-derived free radicals in postischemic tissue injury. N. Engl. J. Med. 312: 159, 1985.

13. McCord, J. M., and Roy, R.S. The pathophysiology of superoxide: Roles in inflammation and ischemia. Canad. J. Physiol. Pharmacol. 60: 1346, 1982.
14. Morganroth, M. L., Reeves, R. T., Murphy, R. C., and Voelkel, N. F. Leukotriene synthesis and receptor blockers block hypoxic pulmonary vasoconstriction. J. Appl. Physiol. 56: 1340, 1984.

15. Morganroth, M. L., Till, G. O., Kunkel, R. G., and Ward, P. A. Complement and neutrophil mediated injury of perfused rat lungs. Lab. Invest. 54: 507, 1986.

16. Myers, C. L., Weiss, S. J., Kirsh, M. M., and Shlafer, M. Involvement of hydrogen peroxide and hydroxyl radical in the "oxygen paradox:" Reduction of creatine kinase release by catylase, allopurinol or deferoxamine, but not by superoxide dismutase. $J$. Mol. Cell. Cardiol. 17: 675, 1985.

17. Parks, D. A., Bulkley, G. B., Granger, D. N., Hamilton, S. R., and McCord, J. M. Ischemic injury in the cat small intestine: Role of superoxide radicals. Gastroenterology 82: 9, 1982.

18. Parks, D. A., and Granger, D. N. Ischemia-induced vascular changes: Role of xanthine oxidase and hydroxyl radicals. Amer. J. Physiol. 245: G285, 1983.

19. Tate, R. M., Vanbenthuysen, K. M., Shasby, D. M., McMurtry, I. F., and Repine, J. E. Oxygen-radicalmediated permeability edema and vasoconstriction in isolated perfused rabbit lungs. Amer. Rev. Respir. Dis. 126: 802, 1982.

20. Till, G. O., Johnson, K. J., Kunkel, R., and Ward, P. A. Intravascular activation of complement and acute lung injury. Dependency on neutrophils and toxic oxygen metabolites. J. Clin. Invest. 69: 1126, 1982.

21. Ward, P. A., Till, G. O., Kunkel, R., and Beauchamp, C. Evidence for role of hydroxyl radical in complement and neutrophil dependent tissue injury. J. Clin. Invest. 72: 789, 1983.

22. White, G. J. Inhibition of oxidative enzymes by anti-allergy drugs. Agents Actions 11: 503, 1981. 